\title{
Tables and Maps
}

TAB LES

2-1. Percentage Shares of World Manufacturing

Production / 26

3-1. Gross Expenditures, $1887-1907 / 131$

3-2. Gross Revenues, $1887-1907 / 132$

3-3. Gross Expenditures vs. Gross Revenues, $1887-1907 / 133$

4-1. The Diffusion of Sea Power, 1896-19o6/153

4-2. The Naval Balance in Asia, 1901/177

5-1. Distribution of British Regular Army / 277

M A P S

British Naval Facilities, $1900 / 136$

Afghanistan / 210 
